\title{
Swimming behavior and velocities of barnacle cyprids in a downwelling flume
}

\author{
Claudio DiBacco ${ }^{1, *}$, Heidi L. Fuchs ${ }^{2}$, Jesús Pineda ${ }^{3}$, Karl Helfrich ${ }^{3}$ \\ ${ }^{1}$ Fisheries and Oceans Canada, Bedford Institute of Oceanography, PO Box 1006, Dartmouth, Nova Scotia B2Y 4A2, Canada \\ ${ }^{2}$ Institute of Marine and Coastal Sciences, Rutgers University, New Brunswick, New Jersey 08901, USA \\ ${ }^{3}$ Woods Hole Oceanographic Institution, Woods Hole, Massachusetts 02543, USA
}

\begin{abstract}
It has been proposed that barnacle cyprids can maintain position in shorewardpropagating fronts by swimming upward against a downwelling flow, potentially mediating onshore transport of larvae toward intertidal habitat. This study developed a novel flume to characterize swimming behavior of barnacle cyprids in a laboratory downwelling flow. Seawater was pumped through a cylindrical observation chamber fitted with diffusers to produce a homogeneous downwelling velocity field. The flume generated plug flow with mean downwelling velocities (indicated by negative sign) of 0 to $-47.3 \mathrm{~mm} \mathrm{~s}^{-1}$. Behavior experiments were done with wild Semibalanus balanoides cyprids. Vertical swimming rates and behaviors were estimated from video observations, and a mixture model was used to estimate velocity distributions for distinct behavioral modes. Larvae exhibited multiple behaviors but typically swam upward in response to downwelling, with a maximum estimated vertical velocity of $72.3 \mathrm{~mm} \mathrm{~s}^{-1}$. When faced with downwelling flows, cyprids alternated between upward swimming and downward swimming to maintain their vertical position in the chamber. As downwelling velocities increased, cyprids that remained in the field of view of the cameras exhibited faster mean upward swimming velocities. It is unclear how long individual $S$. balanoides cyprids can maintain depth, but cyprids were able to maintain depth throughout the 2 min observation period. This study supports earlier hypotheses based on field observations by demonstrating that $S$. balanoides cyprids swim well enough to counter downwelling velocities characteristic of convergence zones. Swimming against downwelling flow could be an adaptive behavior that enables shoreward transport in the absence of any larval ability to swim toward shore or even to sense its direction.
\end{abstract}

KEY WORDS: Downwelling flume $\cdot$ Barnacle $\cdot$ Cyprids $\cdot$ Semibalanus balanoides $\cdot$ Convergence zones $\cdot$ Larval behavior

Resale or republication not permitted without written consent of the publisher

\section{INTRODUCTION}

For planktonic larvae of coastal species to locate a suitable juvenile or adult habitat, they often must complete a cross-shelf migration towards shore. Most invertebrate larvae are slow swimmers $(\sim 1$ to $10 \mathrm{~mm}$ $\mathrm{s}^{-1}$, Chia et al. 1984) that often cannot make headway against horizontal ocean currents, so horizontal advection of larvae on the continental shelf relies on currents generated by physical forcing such as winds, tides and buoyancy differences (Scheltema 1986, Shanks 1995a). For example, some larvae exploit vertical shear in the water column by maintaining their position at depths with persistent and preferential flow direction (Epifanio 1988). Some organisms that migrate between embayments and coastal habitats exhibit rhythmic vertical migratory behavior synchronized with tidal phase (selective tidal stream transport) to mediate net transport (DiBacco et al. 2001, Epifanio \& Garvine 2001). Such adaptive behaviors may have evolved to exploit predictable patterns of flow and increase the chance that larvae reach suitable settlement sites and adult habitat. 
Cross-shelf larval transport could be mediated by physical mechanisms that accumulate planktonic larvae in surface convergent zones that subsequently propagate onshore (Shanks 1983, Helfrich \& Pineda 2003, Scotti \& Pineda 2007). Convergent zones are associated with physical features such as internal waves (Shanks 1983), internal tidal bore warm fronts (Pineda 1994), upwelling relaxation fronts (Farrell et al. 1991), and estuarine fronts (Eggleston et al. 1998). These mechanisms all exhibit converging surface flows that accumulate flotsam and produce strong vertical (downward) flows in the convergence zones. Larvae that are entrained and retained in these convergent zones may experience net horizontal transport shoreward as long as the onshore horizontal current speed $(u)$ is faster than the propagation speed $(c)$ of the convergent front (see Pineda 1999).

In convergent zones generated by surface currents, entrainment is most likely for organisms that inhabit or migrate into surface waters. Once entrained, positively buoyant organisms or those that swim upward may be retained within downwelling zones, ultimately forming dense larval aggregations in surface layers of frontal zones (Shanks 1995a, Pineda 1999). Pineda (1999) characterized hydrodynamic circulation and larval distributions within internal tidal bore warm fronts off the coast of La Jolla, California. He observed cyprids of 2 barnacle taxa (Chthamalus spp., Pollicipes polymerus) concentrated in frontal convergent zones despite downwelling currents, while bryozoan larvae (Membranipora spp.) were not concentrated in the front. Pineda (1999) suggested the cyprids could maintain their position within convergent zones because they swam well enough to counter downwelling velocities, whereas bryozoan larvae would be prevented from accumulating in the front because of their limited swimming abilities and negative buoyancy.

Numerous field studies provide evidence that convergence zones propagating across the continental shelf can transport larvae into shallow-water intertidal habitats. This evidence includes: (1) higher concentrations of larvae sampled within internal wave convergent zones (slicks) than outside these zones (Shanks 1988, Pineda 1999), (2) shoreward transport of buoyant flotsam and surface drifters within convergent zones (Shanks \& Wright 1987), and (3) strong correlations between daily settlement of larvae in intertidal habitats and the occurrence of processes featuring convergent zones impinging the shore (Shanks 1985, 1986, Pineda 1991). Note, however, that local concentration of particles by internal wave convergences does not imply transport, as pointed out by Franks (1997). Although field evidence is circumstantial, laboratory experiments and numerical analyses of stratified flow provide more tangible evidence that buoy- ant gravity currents, characterized by a convergent front, can lead to accumulation and transport of buoyant particles in the direction of the propagating front (Franks 1997, Helfrich \& Pineda 2003). For larvae to be transported, however, they must have a behavioral mechanism that promotes entrainment in convergent zones that propagate shoreward. The purpose of the present study was to test the hypothesis that barnacle larvae can swim well enough vertically to counter downwelling currents associated with surface convergent flows.

A direct test of this hypothesis would require simultaneously measuring vertical velocities of both flow and larvae within a convergent zone. Such measurements are infeasible at sea where it is difficult to measure flow fields near the air-sea interface and even more difficult to locate, observe and identify microscopic larvae that are sparse in situ. Because of such challenges, larval swimming behavior has rarely been studied under natural field conditions (but see Shanks 1985, 1995b, Fuchs et al. 2010), and larval swimming velocities are usually estimated in controlled laboratory experiments (reviewed by Chia et al. 1984). In still-water experiments, swimming is often observed over very short temporal (s) and spatial $(\mathrm{cm})$ scales. On these scales, observed swimming bursts or cruising may poorly represent the sustained vertical swimming rates that organisms would need to maintain their positions within downwelling zones. An alternative method is to expose larvae to currents of known magnitude in a flume and to measure the individual's behavioral responses to varying flow fields, but most flumes produce only horizontal currents atypical of convergence currents and lack the vertical currents typical of convergence zones. An experimental test of our hypothesis required the development of a new method for generating downwelling flow in the laboratory.

This paper describes a novel flume used to measure sustained vertical swimming speeds and behavior of cyprids of the wild barnacle Semibalanus balanoides in a downwelling flow. The flume was designed to simulate constant velocity flow fields (plug flows) in an experimental chamber that could be used to assess swimming abilities (e.g. maximum sustained swimming rates) and behavioral responses (i.e. rheotaxis) of barnacle larvae exposed to specified flow conditions. Characteristic flow fields and calibration data are presented along with a preliminary study that characterized sustainable swimming rates of late-stage cyprids. Larvae were exposed to a range of downwelling water velocities, their movements were recorded with digital video cameras, and the images were analyzed with particle tracking software to determine behavioral responses and sustained swimming rates. 


\section{MATERIALS AND METHODS}

Downwelling flume. Larval swimming experiments were conducted in a downwelling flume constructed at the Rinehart Coastal Research Center at the Woods Hole Oceanographic Institution (WHOI). The flume is a closed system with a vertically oriented observational channel constructed from an acrylic pipe $\sim 90 \mathrm{~cm}$ in length and $30 \mathrm{~cm}$ in diameter (Fig. 1). The ends of this channel were capped with removable acrylic plates fitted with PVC fittings and pipes to introduce and drain water from the top and bottom of the chamber, respectively. Seawater is circulated through the observational channel at variable flow rates by an inline, continuous duty, variable-speed pump and $\mathrm{AC}$ drive controller. Two diffusers located at the top of the observational channel, $\sim 15 \mathrm{~cm}$ from the top where water enters the channel, were used to disperse the flow and create a relatively uniform cross-sectional and longitudinal flow field in the lower two-thirds of the channel (see 'Results'). The first diffuser consisted of ca. $1 \mathrm{~cm}$ diameter glass beads packed in a conical arrangement to disperse the initial jet of water, while the second diffuser consisted of a perforated (ca. $1 \mathrm{~mm}$ diameter holes), $1.25 \mathrm{~cm}$ acrylic plate positioned below the conical diffuser. The observational chamber was placed inside a $325 \mathrm{l}$ acrylic box that served as a water jacket to help maintain a constant seawater temperature inside the chamber. This water jacket was designed as a flow-through system for ambient seawater, but it could be adapted to circulate water from a reservoir maintained at specific temperatures with supplemental chillers or heaters. The square water jacket also helped correct image distortion resulting from light diffraction due to the larval chamber's cylindrical shape.

The bottom of the observation chamber was fitted with stainless steel tubes (ports) for injecting larvae and tracer particles. Injection ports allowed the flume to remain a closed system, which helped maintain experimental conditions. Injection tubes were roughly centered in the channel's cross-section and could be

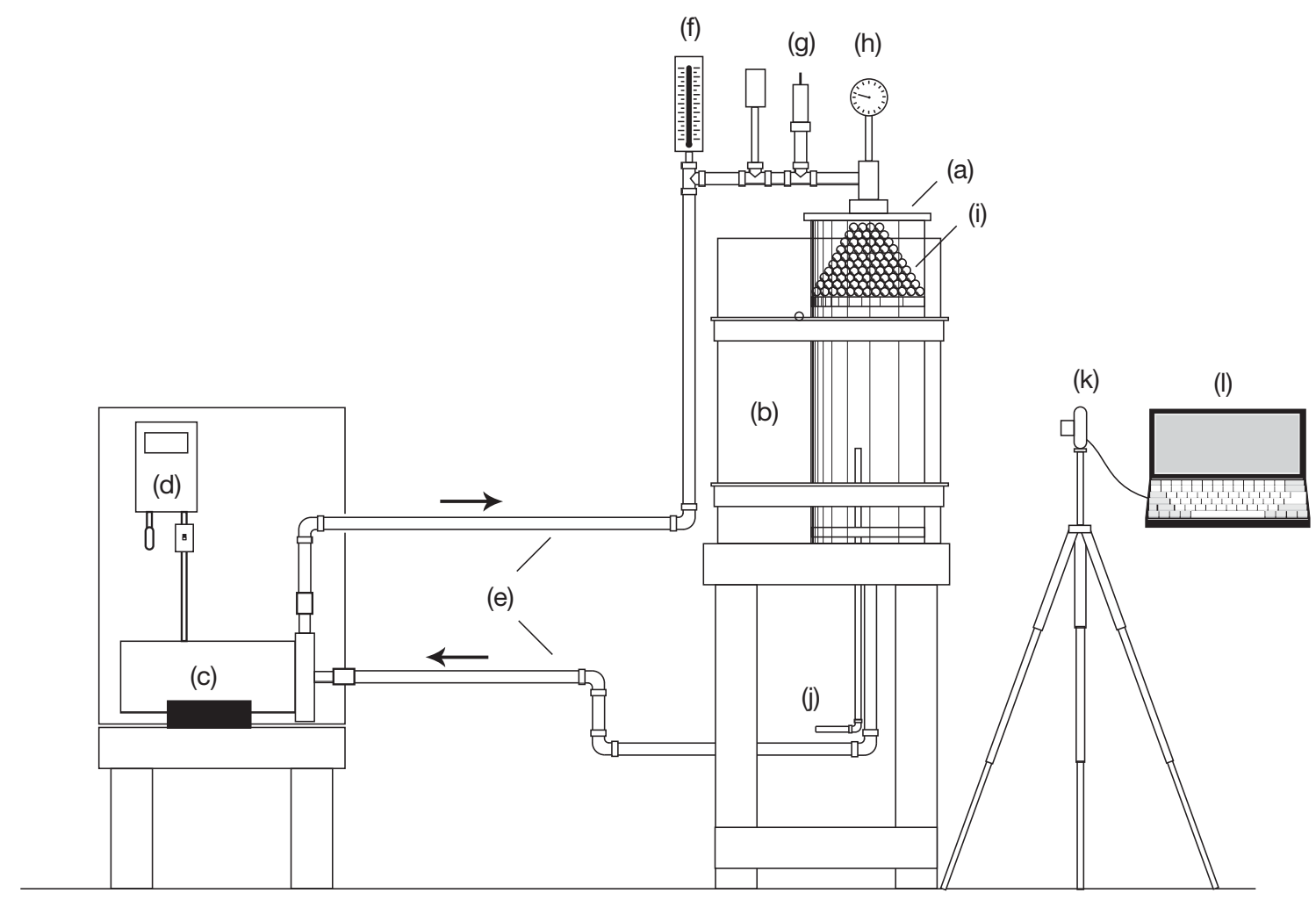

Fig. 1. Downwelling flume. The downwelling chamber (a) sits in a water jacket (b) that receives ambient seawater through-flow to regulate and maintain water temperature in the chamber. The water pump (c) and dual range frequency controller (d) regulate the speed that seawater is recirculated through the flume. The pump is connected to the downwelling chamber via an integrated, closed system of $2.54 \mathrm{~cm}$ PVC pipe and hose (e). PVC pipe connected to entrance of the chamber is fitted with an in-line thermometer (f), pressure release valve (g) and pressure gauge (h) to monitor chamber conditions. Diffusers (i) located at the top of the observational channel dispersed the flow and helped to create a relatively homogeneous flow field in the lower two-thirds of the channel. The bottom of the chamber is fitted with a retractable larval injection port (j) used to introduce larvae into the chamber during experiments. Two orthogonally positioned video cameras ( $\mathrm{k}_{;} 1$ camera shown) and a computer (l) were used to capture digital images for particle tracking analysis of larval behavior and swimming velocities 
raised and lowered to introduce larvae or particles into preferred observational regions along the channel's longitudinal axis. The injection tubes were retracted before experimental runs to minimize flow field disruptions.

When ambient seawater was used in the flume, bubbles formed on the inside wall of the observational chamber. Bubble formation was attributed to degassing of cold seawater as it was recirculated through the diffuser and perhaps even a slight warming of the seawater. This problem was minimized by partially degassing seawater before filling the flume by holding it at room temperature $\left(15\right.$ to $\left.20^{\circ} \mathrm{C}\right)$ for 12 to $24 \mathrm{~h}$ in a sterilized, high density polyethylene holding tank. Once the seawater had degassed and equilibrated to room temperature and pressure, it was pumped into the flume and cooled to ambient ocean temperatures with the aid of the water jacket. An inline thermometer was used to check that the flume's seawater had returned to ambient ocean temperatures before larvae were introduced and swimming experiments were conducted.

Flow velocity characterization. Mean downwelling velocity fields for the observational chamber were determined for a range of pump rates with a laser Doppler velocimeter (LDV, Dantec Dynamics). All calibrations were done before the behavior experiments to ensure that a relatively homogenous and predictable flow field was generated and to correlate downwelling velocities with their associated pump rates. For all LDV calibrations, the tank was filled with filtered seawater and seeded with hollow glass beads (Sontek) that had a nominal diameter of 4 to $20 \mu \mathrm{m}$ (density, $\rho=1.05 \mathrm{~g}$ $\mathrm{m}^{-3}$ ). The flume was allowed to run for 5 to $10 \mathrm{~min}$ before measuring vertical and horizontal velocities at each of 42 points $(\mathrm{N}=2000$ to 10000 estimates per point) on a $12.1 \times 56.9 \mathrm{~cm}$ sampling grid (Fig. 2) covering half the focal plane of the larval video frame. Velocity gradients at the chamber walls (e.g. Vogel 1994) were not measured. The flow was assumed to be symmetric and the other half of the video frame was not characterized. Vertical flow velocities were measured at each LDV sampling point for a series of 7 pump rates: 500, 750, 1000, 1250, 1500, 2000 and $2500 \mathrm{~Hz}$. Horizontal velocities could not be measured
B

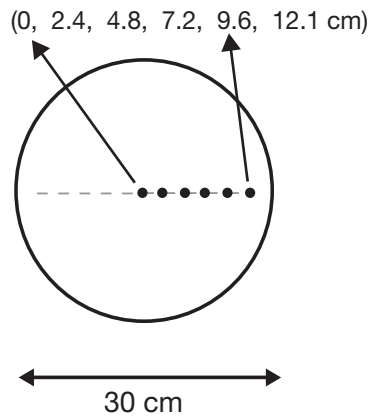

C

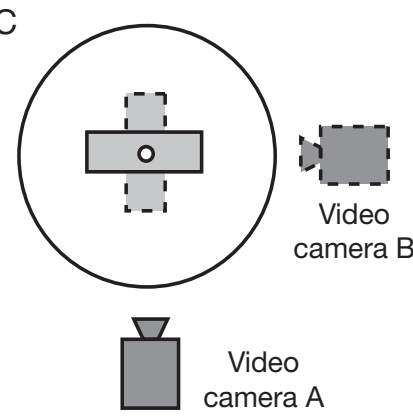
sampling grid intersects $(\bullet)$ indicate locations of laser Doppler velocimeter V) measurements. Grid point row number (1 to 7 in square brackets) and the grid and chamber was not characterized with the LDV and was assumed to be equivalent to the right side. Laser measurements included $N=2000$ to 10000 per grid point. Larval video observations were recorded in a focal plane ocation of LDV grid points relative to the chamber's walls and distance of each approximate focal depth (shaded rectangles) of 2 orthogonally positioned digital video cameras and cross section and position of the larval injection tube (O)

with the LDV owing to technical difficulties. LDV measurements were completed before larval observations to avoid any interference of laser-seeding particles with larval swimming behavior and rates. Interpolated mean downwelling flow fields of the flume's observational chamber are contoured along with corresponding estimates of flow field variability, expressed as standard deviations (SDs) in the flow.

Pliolite ${ }^{\circledR}$ particles (diameter 100 to $200 \mu \mathrm{m}, \rho=1.026$ $\mathrm{g} \mathrm{cm}^{-3}$ ) (Eliokem, http://eliokem.com) were employed to measure downwelling velocities at a pump rate of $300 \mathrm{~Hz}$. The Pliolite ${ }^{\circledR}$ particles were mixed throughout the chamber and subsequently maintained under noflow conditions for about 15 min to allow heavier particles to settle, leaving only apparently neutrally buoyant particles in suspension. The remaining particles 
were video recorded first with the pump switched off and then with the pump turned on. The video series with and without pumping included most of the same particles because the estimated gravitational sinking rates of the particles were very low $\left(0.74 \pm 0.12 \mathrm{~mm} \mathrm{~s}^{-1}\right.$, mean $\pm \mathrm{SD}$ ) and no movement was detectable by eye. Video recordings of Pliolite ${ }^{\circledR}$ particles with and without pumping were analyzed with particle tracking software to estimate vertical and horizontal velocities. A linear regression between pump rates $(\mathrm{Hz})$ and resultant mean downwelling velocity estimates derived from seeding with glass beads and Pliolite ${ }^{\circledR}$ is presented in 'Results' (see Fig. 3).

Larvae. Semibalanus balanoides cyprids were collected at the WHOI pier, Woods Hole, Massachusetts, on 4 and 24 March 2004. Species identification and sampling dates are consistent with observations of S. balanoides larvae between January and March (Pineda et al. 2002). Zooplankton were sampled within $75 \mathrm{~cm}$ of the surface with a $200 \mu \mathrm{m}$ mesh plankton net. Samples were concentrated in a 301 cooler filled with $100 \mu \mathrm{m}$ filtered ambient seawater and transported back to the laboratory within 10 min of being collected. In the laboratory, cyprids were initially separated from other plankton by projecting a bright light $\sim 3 \mathrm{~cm}$ below the water level onto the inside wall of the cooler. Cyprids aggregated near the reflected light where they were siphoned with a large bore tube and concentrated into 11 beakers containing ambient, filtered $(20 \mu \mathrm{m})$ seawater. Cyprids were isolated with large bore pipettes and dissecting microscopes. Once sorted, cyprids were held in filtered seawater $(20 \mu \mathrm{m})$ and maintained in the dark at ambient ocean temperatures (ca. $5.5^{\circ} \mathrm{C}$ ) until they were used in larval behavior experiments. Similar dark and cold conditions had no significant effect on swimming behavior of Balanus amphitrite cyprids and prevented settlement and metamorphosis for $7 \mathrm{~d}$ (Amsler et al. 2006). All laboratory experiments were completed within $32 \mathrm{~h}$ of field collections.

Experimental design. Two experiments were conducted to observe Semibalanus balanoides cyprid swimming behavior and to measure mean sustained swimming rates. Flume experiments were conducted on 4 and 24 March 2004. Cyprids were introduced into the downwelling chamber for each of a predetermined series of downwelling velocity treatments corresponding to prescribed pump rates (Table 1). Cyprids were exposed to downwelling flume velocities (indicated by negative sign) that ranged from 0 to $-41.5 \mathrm{~mm} \mathrm{~s}^{-1}$ and from 0 to $-47.3 \mathrm{~mm} \mathrm{~s}^{-1}$ during laboratory experiments conducted on 4 and 24 March 2004, respectively (see Table 3). Larvae were added to the chamber before each run to ensure a large number of observations, but the number of larvae remaining in the camera's field of
Table 1. Summary of downwelling water velocity (indicated by negative sign) measured in the observational region of the downwelling flume $(-29.4 \mathrm{~cm}$ and $-58.8 \mathrm{~cm}$; see Fig. 2) with a laser Doppler velocimeter (LDV). Pump rate (Hz) specific parameters are the mean, SD, minimum and maximum downwelling velocities $\left(\mathrm{mm} \mathrm{s}^{-1}\right)$. The downwelling velocity was assumed to be $0 \mathrm{~mm} \mathrm{~s}^{-1}$ when the pump was off (pump rate $=0 \mathrm{~Hz}$ )

\begin{tabular}{|ccccc|}
\hline $\begin{array}{l}\text { Pump } \\
\text { rate } \\
(\mathrm{Hz})\end{array}$ & $\begin{array}{c}\text { Mean } \\
\text { velocity } \\
\left(\mathrm{mm} \mathrm{s}^{-1}\right)\end{array}$ & $\begin{array}{c}\text { SD } \\
\left(\mathrm{mm} \mathrm{s}^{-1}\right)\end{array}$ & $\begin{array}{c}\text { Minimum } \\
\text { velocity } \\
\left(\mathrm{mm} \mathrm{s}^{-1}\right)\end{array}$ & $\begin{array}{c}\text { Maximum } \\
\text { velocity } \\
\left(\mathrm{mm} \mathrm{s}^{-1}\right)\end{array}$ \\
\hline 300 & -5.11 & 1.63 & -9.90 & 8.34 \\
500 & -8.10 & 2.12 & 5.71 & 11.51 \\
750 & -14.36 & 2.50 & 11.32 & 18.61 \\
1000 & -18.81 & 2.67 & 13.24 & 24.99 \\
1250 & -25.28 & 2.99 & 20.78 & 29.43 \\
1500 & -29.12 & 3.48 & 24.11 & 34.05 \\
2000 & -41.48 & 3.19 & 34.75 & 50.43 \\
2500 & -47.29 & 3.05 & 42.42 & 52.89 \\
\hline
\end{tabular}

view typically fell to $<20$ individuals by the end of the 2 min observation period.

The number of larvae available for laboratory experiments was limited by the time required to sort cyprids from field samples and because individual larvae were used in only one replicate treatment. On each experimental date, still water and 6 or 7 downwelling rates were used, of which still water and 2 other treatments were replicated. All treatments were replicated on both experimental dates except that the $2500 \mathrm{~Hz}$ treatment was conducted only on 24 March.

Once larvae had been introduced into the downwelling chamber, they could not be removed from the flume without draining the system. Refilling the tank and acclimating seawater temperature required about $5 \mathrm{~h}$, so draining the system between treatments was impractical. Instead the observational chamber was purged of larvae between replicate treatments by running the system at high speed until all larvae were overwhelmed and flushed from the chamber.

Since cyprids are positively phototactic (see Crisp 1955), faint background lighting was maintained by turning off overhead lights in the vicinity of the flume during larval swimming experiments. Overhead lighting was expected to elicit an upward swimming response a priori, but observations were consistent with swimming behavior that maintained larval position in the water column. To video record the larvae, the observation area was backlit with a fluorescent lamp positioned directly opposite the camera. Before each experimental run, the recirculating pump and fluorescent light sources were switched off. The pump was preset to start pumping at the specified downwelling velocity once switched back on. The larval injection tube was raised and centered in the video 
camera's field of view (ca. $15 \mathrm{~cm}$ wide $\times 11 \mathrm{~cm}$ high) to seed the observational region of the chamber. About $100 \mathrm{ml}$ of seawater was gently injected into the chamber until ca. 100 to 200 larvae were visible in the camera's field of view. Larvae were allowed several minutes to reorient themselves and assume a normal swimming behavior before the fluorescent lights and the pump were turned on. The flume's flow field was allowed time to establish and stabilize; calibration studies (with Pliolite ${ }^{\circledR}$ and LDV) indicated that $<10 \mathrm{~s}$ were required to reach maximum flow velocities at pump rates used in this study (250 to $2500 \mathrm{~Hz}$, corresponding to 5.1 to $47.3 \mathrm{~mm} \mathrm{~s}^{-1}$ downwelling velocities). During larval swimming experiments, downwelling velocities were estimated from the pump calibration rather than by LDV to avoid potential effects of the laser or glass seeding on larval behavior.

The video field of view was narrower than the flume width to avoid visual artifacts associated with the chamber's curved walls. The effect of flume walls on larval swimming rate or behavior is unknown. As a precaution, swimming behavior was video recorded in the middle of the chamber (Fig. 2) where mean downwelling velocities were free of wall effects, spatially uniform and temporally stable. The fields of view of 2 cameras (A and B) were at least $6.5 \mathrm{~cm}$ from the wall; the mean $( \pm \mathrm{SE})$ width and height of the field of view averaged across replicate experiments and camera views were $14.7 \pm 2.0 \mathrm{~cm}$ and $10.9 \pm 2.0 \mathrm{~cm}$, respectively.

Larval velocity measurements. Swimming larvae and Pliolite ${ }^{\circledR}$ particles were video recorded with a black and white digital camera (Hitachi, model KPF120 with square pixels and $1390 \times 1040$ resolution), and images were captured with XCAP-Std software. A capture rate of 6 frames per second (fps) was selected to limit the distance that larvae or particles were displaced between consecutive frames and to facilitate tracking of individual larvae and particles. Video sequences were about 2 min long and were limited by the size of the computer's RAM memory. Particle tracking software was used to analyze digital video recordings and estimate vertical and horizontal swimming rates of Semibalanus balanoides cyprids. Individual larval and particle trajectories were constructed with Matlab software described in Fuchs et al. (2004). Larval positions were determined to subpixel accuracy from the centroid of groups of pixels (typically 10 to 20 per larva) in binarized images. Still images of the larval injection tube located in the camera's focal plane were saved to serve as as a scale bar before conducting larval swimming experiments. Travel distances were scaled from the width of the larval injection tube of known diameter $(8.0 \mathrm{~mm})$. Improbable larval trajectory segments were removed manually. Any larvae that were not retained within the camera's focal plane for at least $1 \mathrm{~s}$ were excluded from the data analyses.

After trajectories were constructed, swimming speeds were determined based on an individual's net displacement between consecutive digitized images (i.e. distance traveled in $\frac{1}{6} \mathrm{~s}$ ). The error in the vertical swimming speeds (i.e. frame to frame displacement) is estimated to be about $10 \%$. The horizontal maximum field of view used was $175 \mathrm{~mm}$ giving $0.126 \mathrm{~mm}$ pixel $^{-1}$. Thus, a swimming speed of $5 \mathrm{~mm} \mathrm{~s}^{-1}$ results in displacement of 6.6 pixels in $1 / 6 \mathrm{~s}$. Centroids of particles can be estimated to an accuracy of 0.1 to 0.25 pixels (Wernet \& Pline 1993) giving an uncertainty in the displacement of about $10 \%$ using a 0.25 pixel error in both the initial and final positions. Additional error in the estimated larvae swimming speeds will arise from turbulent fluctuations and gradients in the mean fluid velocity within the camera's field of view (see Figs. 3 \& 4 and 'Discussion' below). The turbulent fluctuations are $<2 \%$ of the mean vertical velocities in the field of view and will have a small effect on the mean vertical swimming speed estimates. The mean flow gradients will be a more significant source of uncertainty, but since larval tracks occupy the field of view, these variations should be reduced when larval speeds are averaged.

We could not use all velocity measurements from individual tracks because they were dependent and biased toward slower individuals that spent more time in the video frame. To analyze only independent, unbiased data, we took a single point estimate from nearest the center of the larval trajectory as the representative velocity. All single point estimates were used to estimate the mean and variance of swim speed in each treatment and to assess behaviors (see 'Larval behavior analysis' below). Both vertical and horizontal swimming velocities were quantified from barnacle larval tracks. These components were not combined to produce 3-dimensional vectors and associated 'true' swimming velocities because those detailed analyses were beyond the scope of the present study. The vertical swimming rates reported here are accurate, but they are conservative estimates of actual swimming velocities since larvae were moving in 3 dimensions.

Corrected mean vertical swimming velocities were related to flume downwelling velocities by linear regression analysis. Because the cyprids used in each experiment were collected in situ about $3 \mathrm{wk}$ apart, a general linear model (GLM) was used to test whether the slopes and intercepts of regression equations were significantly different for 2 independent laboratory experiments.

Larval behavior analysis. Larval swimming tracks showed qualitatively that cyprids exhibited multiple behaviors. Some larvae moved in a slow wobble, for 
example, whereas some alternated between slow swimming and passive sinking, and others moved faster in tortuous loops. Different behaviors were also detectable as multiple peaks in histograms of larval vertical velocity. We assumed that larvae have multiple distinct behavior modes and that within a given mode larval velocities are normally distributed. On this assumption, the frequency distribution of larval velocities in each treatment represents a normal mixture. This mixture can be analyzed statistically to separate individual behavior modes and to estimate the velocity distribution within each mode. A similar approach was used in Fuchs et al. (2004) to estimate the proportions of larvae that were swimming, hovering or sinking in the presence of turbulence. Here we can ignore turbulence because diffusion is negligible compared with advection (see 'Results: Chamber calibration').

We assume that larvae have $g$ behavior modes and that within each mode the instantaneous vertical velocities are normally distributed with mean $\mu_{i}$ and variance $\sigma_{i}{ }^{2}$, where $i$ indicates the mode number. The probability density of observed larval velocity is given by

$$
f(x ; \phi)=\sum_{i=1}^{g} \pi_{i} f_{i}\left(x ; \theta_{i}\right)
$$

where $f_{i}\left(x_{i} \theta_{i}\right)$ is the normal probability density function for component $i$ with parameter vector $\theta_{i}=\left[\mu_{i}, \sigma_{i}\right]$, $\pi_{i}$ is the mixing proportion for component $i$, and $\phi=(\pi$, $\theta$ ), where $\pi$ and $\theta$ are the vectors of $\pi_{i}$ and $\theta_{i}$. The goal is to estimate the mixture parameters $\phi$ from the observed larval velocities. We can estimate $\phi$ for a specified number of behavior modes $g$ by using an expectation-maximization algorithm (e.g. McLachlan \& Peel 2000 ) to maximize the log-likelihood of $f$.

Here the number of modes is unknown, so we estimated $g$ by using a likelihood ratio to test the null hypothesis $H_{0}: g=g_{0}$ against the alternative hypothesis $H_{1}: g=g_{0}+1$ for $g_{0}=1$ to 6 . The null hypothesis is rejected if the test statistic

$$
\Lambda=2\left[L\left(\phi_{1}^{\prime}\right)-L\left(\phi_{0}^{\prime}\right)\right]
$$

is large, where $L\left(\phi_{0}^{\prime}\right)$ and $L\left(\phi_{1}^{\prime}\right)$ are the log-likelihoods for parameter estimates under $H_{0}$ and $H_{1}$, respectively, and prime symbols denote maximum likelihood estimates. Because $\Lambda$ does not follow its usual $\chi_{v}^{2}$ distribution for mixture models, we estimated the null distribution function of $\Lambda$ using a bootstrap (McLachlan 1987). The estimated number of modes $g^{\prime}$ was taken to be the smallest $g_{0}$ for which $H_{0}$ could not be rejected at a significance level $\alpha=0.03$. Analyses were done in Matlab 2008 with the Statistics toolbox. Finally, we corrected the estimated mean vertical velocities $\left(\mu_{i}^{\prime}\right)$ of each behavior mode by subtracting the downwelling velocity.

\section{RESULTS}

\section{Chamber calibration}

Mean water velocities measured in the observational region of the flume's downwelling chamber ranged from -5.11 to $-47.29 \mathrm{~mm} \mathrm{~s}^{-1}$ (downward direction indicated by negative value) corresponding to pump rates of 300 and $2500 \mathrm{~Hz}$ (Table 1, Fig. 3). Downwelling velocities were assumed to be $0 \mathrm{~mm} \mathrm{~s}^{-1}$ when the pump was turned off. The water-diffusing region (WDR) at the top of the chamber evenly spread the flow from the $5 \mathrm{~cm}$ diameter inflow pipe into the $30 \mathrm{~cm}$ diameter chamber without producing a jet (see 'Inflow', Fig. 2). Velocity fields interpolated from LDV data were relatively uniform throughout the observational chamber (Fig. 4A,C) except immediately downstream from the WDR where small-scale turbulence resulted in unpredictable mean velocities and proportionally large variance (SD) in mean flow. The turbulent region immediately below the WDR was thicker at higher pump rates (Fig. 4B,D). This turbulence dissipated quickly and velocities became more uniform with increased distance from the WDR. The ratio of turbulence versus mean flow ( $W_{\mathrm{RMS}} / W$, where $W_{\mathrm{RMS}}$ is the root mean square of vertical velocity) generally decreased at higher downwelling velocities (Fig. 5), including Rows 5 and 6 in the bottom half of the chamber (Fig. 2) where larvae were video recorded. At all pump rates, turbulence generated by the diffusers dissipated quickly and produced a downstream flow field that was nearly uniform across

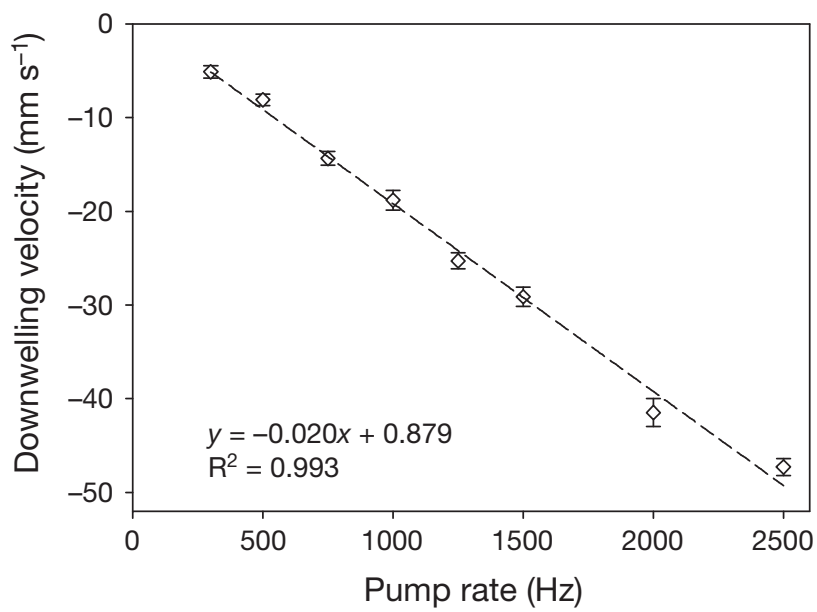

Fig. 3. Measured downwelling velocity $\left(\mathrm{mm} \mathrm{s}^{-1}, \pm 1 \mathrm{SE}\right)$ versus pump rate $(\mathrm{Hz})$ in the flume's observational chamber. Downwelling velocities corresponding to pump rates of $\geq 500 \mathrm{~Hz}$ were measured with a laser Doppler velocimeter (LDV), while velocities corresponding to the $300 \mathrm{~Hz}$ pump rate were measured via image analysis of near-neutrally buoyant Pliolite ${ }^{\circledR}$ particles. Downwelling velocities were averaged from measurements made at sampling grid points in Rows 5 and 6 of the LDV sampling grid (see Fig. $2 ; y=-29.4 \mathrm{~cm}$ and $-44.1 \mathrm{~cm}$ ) 


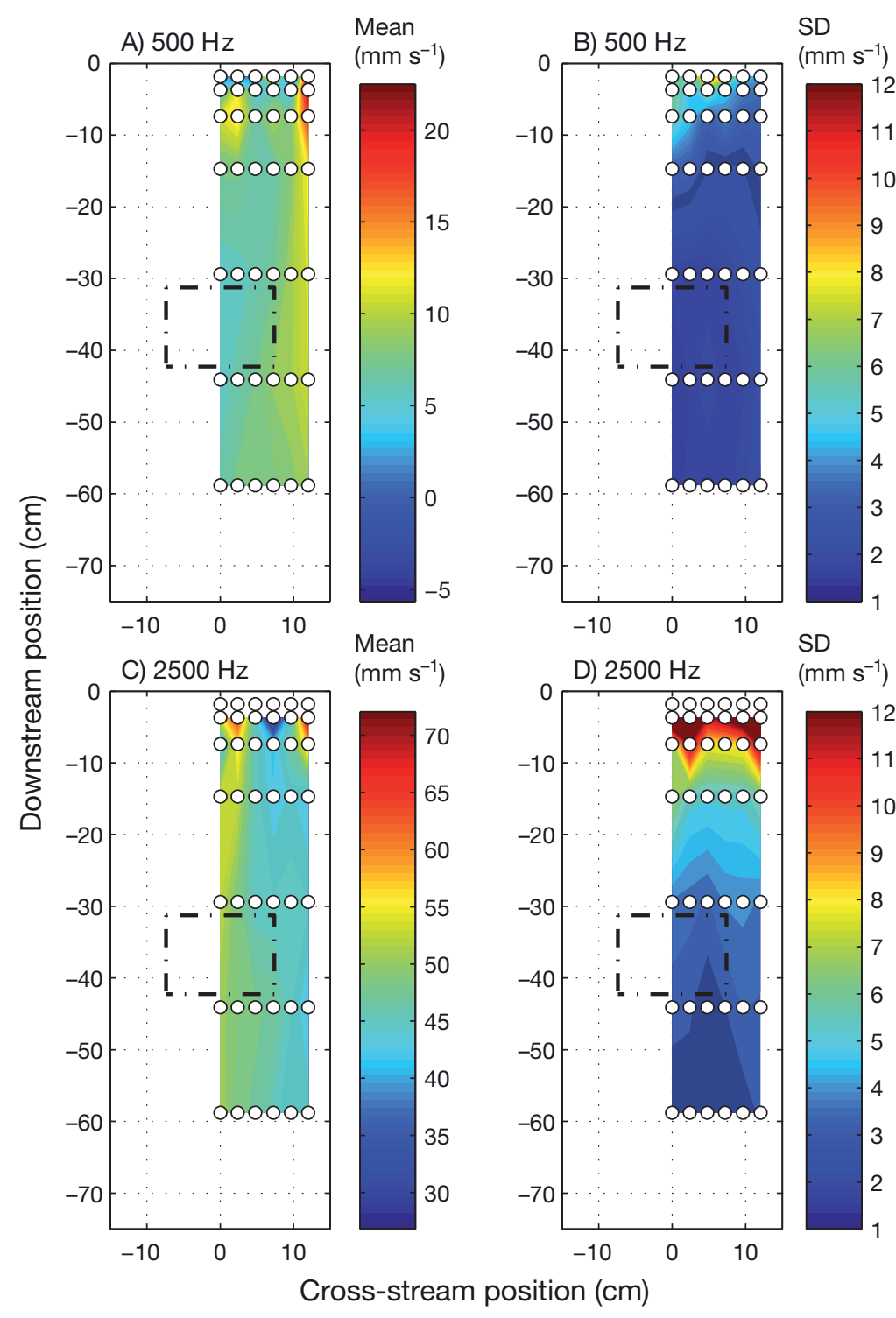

Fig. 4. Contour plots of $(\mathrm{A}, \mathrm{C})$ mean downwelling water velocities $\left(\mathrm{mm} \mathrm{s}^{-1}\right)$ and $(\mathrm{B}, \mathrm{D}) \mathrm{SDs}$ generated at low $(500 \mathrm{~Hz})$ and high $(2500 \mathrm{~Hz})$ flume pump rates. Velocities were measured with a laser Doppler velocimeter (LDV) at specified grid points (O) (see also Fig. 2). Boxes framed by dashed lines indicate the size and position of video fields of view used to record larval swimming velocities and behavior. Note missing data from top row of the sampling grid in plots $\mathrm{C}$ and $\mathrm{D}$ where levels were too high to make accurate LDV measurements

the chamber and consistent with near-plug flow velocity profiles (Vogel 1994). Observed mean horizontal velocities within the field of view ranged from $\sim 0.4$ to $1.4 \mathrm{~mm} \mathrm{~s}^{-1}$ at downwelling rates ranging from 500 to $2500 \mathrm{~Hz}$ (Fig. 4A,C). This variation in mean velocities corresponds to about 5 to $30 \%$ of observed mean cyprid swimming velocities measured at coincident downwelling rates of 500 and $2500 \mathrm{~Hz}$.

Flume pump rates and resultant mean downwelling velocities were highly correlated in all regions of the
LDV sampling grid except Row 1 (Table 2, Fig. 2). Coefficients of determination $\left(\mathrm{r}^{2}\right)$ increased from 0.965 to 0.996 with distance from the WDR (Table 2). Because pump rate and downwelling velocity were so highly correlated, a linear regression model of mean downwelling velocity $(y)$ measured in Rows 5 and 6 versus pump rate $(x)(y=$ $-0.02 x+0.879, r^{2}=0.993$; Fig. 3 ) was adequate for predicting downwelling velocities during larval swimming experiments.

\section{Larval swimming rate}

Mean upward swimming velocities of Semibalanus balanoides cyprids increased as larvae were exposed to greater downwelling water velocities (Fig. 6), implying that larval swimming generally opposed the flume's flow direction. The observed mean vertical velocities reflect net larval movements owing to (1) downwelling flume flow and (2) larval swimming behavior. If larvae acted as passive particles, the observed speeds would be comparable to the flume's downwelling velocity (see 1:1 line, Fig. 6). The corrected mean vertical velocities are adjusted for advection due to downwelling and reflect true cyprid swimming rates. Observed mean vertical velocities were $\sim 0 \mathrm{~mm}$ $\mathrm{s}^{-1}$ under static flume conditions when the pump rate and associated downwelling velocity were zero (Fig. 6). These velocity estimates agree with qualitative observations of cyprids, which appeared to hover in the camera's field of view under static flume conditions. Observed mean vertical velocities were almost always negative under downwelling conditions (Fig. 6), indicating that cyprids experienced net downward transport when exposed to tested downwelling velocities. As the flume's pump rate and corresponding downwelling velocity increased, however, the corrected, true vertical swimming velocities also increased (Fig. 6). Based on a GLM analysis, neither the slopes (GLM: $\mathrm{df}=1, t=$ 1.443, $\mathrm{p}=0.177$ ) nor the intercepts (GLM: $\mathrm{df}=1, t=$ $0.789, p=0.446$ ) of the regressions of corrected mean vertical velocities versus flume downwelling velocity differed between 4 and 24 March (Fig. 6).

Cyprid vertical velocities measured with 2 orthogonally oriented cameras (see Fig. 2C) were comparable (Fig. 7). Correlations between observed and corrected downwelling velocity estimates for Camera A 


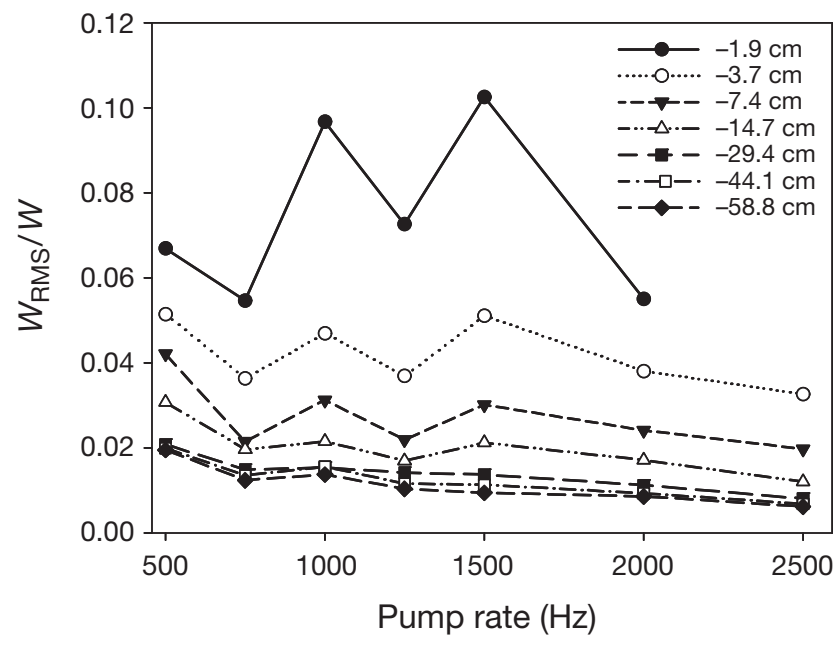

Fig. 5. Ratio of turbulence to mean flow $\left(W_{\mathrm{RMS}} / W\right.$, where $W_{\text {RMS }}$ is the root mean square of vertical velocity) for downwelling velocities estimated with a laser Doppler velocimeter (LDV) along the vertical axis of the downwelling flume's observational chamber. Each plotted line corresponds to a different region of the chamber at a set distance from the diffuser, which is indicated in the legend and corresponds to rows of the LDV sampling grid (Fig. 2)

Table 2. Summary of results for linear regressions of downwelling velocity versus pump rate for rows 1 to 7 of the laser Doppler velocimeter (LDV) sampling grid and for rows 5 and 6 combined, which correspond to the region of the chamber where larval swimming rates and behaviors were video recorded. Regression equation; $y=$ predicted downwelling velocity $\left(\mathrm{mm} \mathrm{s}^{-1}\right), x=$ pump rate $(\mathrm{Hz})$

\begin{tabular}{|lccc|}
\hline Row & $\begin{array}{c}\text { Distance } \\
(\mathrm{cm})\end{array}$ & $\begin{array}{c}\text { Regression } \\
\text { equation }\end{array}$ & $\begin{array}{c}\text { Coefficient of } \\
\text { determination }\left(\mathrm{r}^{2}\right)\end{array}$ \\
\hline 1 & -1.9 & $y=0.01 x-10.043$ & 0.396 \\
2 & -3.7 & $y=-0.02 x+1.520$ & 0.965 \\
3 & -7.4 & $y=-0.02 x+0.096$ & 0.974 \\
4 & -14.7 & $y=-0.02 x+0.726$ & 0.979 \\
5 & -29.4 & $y=-0.02 x+1.027$ & 0.989 \\
6 & -44.1 & $y=-0.02 x+0.731$ & 0.996 \\
7 & -58.8 & $y=-0.02 x+0.829$ & 0.996 \\
$5 \& 6$ & $-29.4 \&-44.1$ & $y=-0.02 x+0.879$ & 0.993 \\
\hline
\end{tabular}

versus Camera B were highly significant for the 4 and 24 March laboratory experiments (Fig. 7). The velocities recorded from Camera B were slightly higher than those from Camera A. The sequences recorded from Camera B were twice as long as those from Camera A and the higher velocities may reflect the loss of weaker swimmers as they were washed out of the frame in later observations.

Cyprids had considerably lower mean horizontal swimming velocities than vertical velocities (data not shown). Horizontal velocities ranged from $\leq 1 \mathrm{~mm} \mathrm{~s}^{-1}$ at flume downwelling rates $<20 \mathrm{~mm} \mathrm{~s}^{-1}$ to a maximum of about $2.6 \mathrm{~mm} \mathrm{~s}^{-1}$ at the highest downwelling velocity

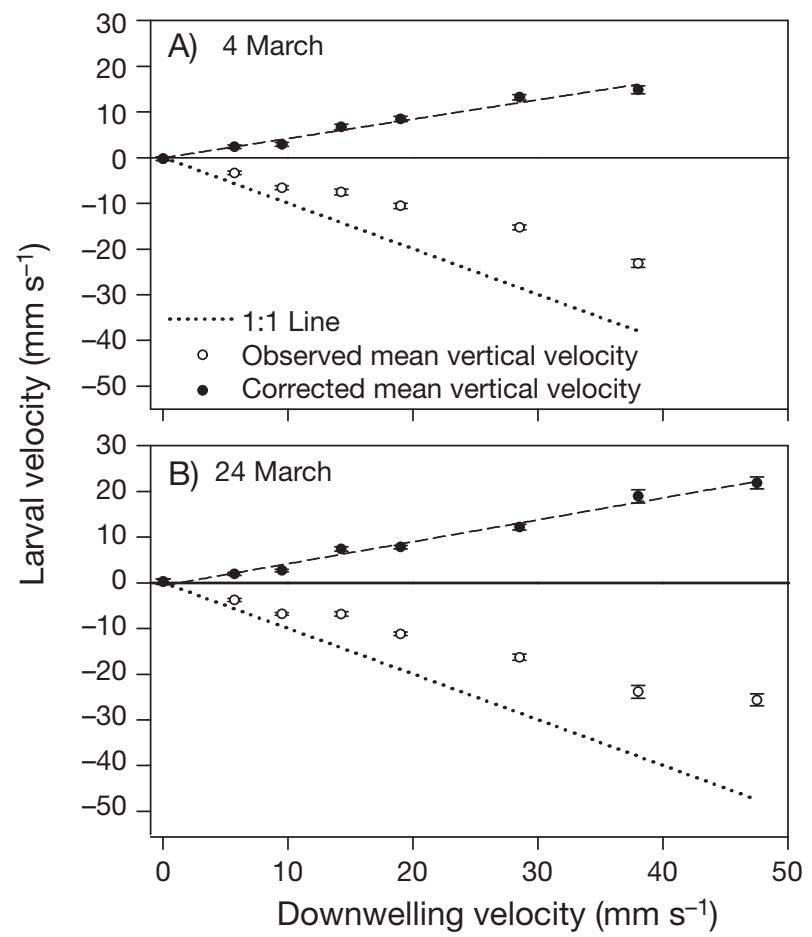

Fig. 6. Semibalanus balanoides. Mean vertical velocity estimates $\left(\mathrm{mm} \mathrm{s}^{-1}, \pm 1 \mathrm{SE}\right.$ ) versus flume downwelling velocities for cyprids tested on (A) 4 March 2004 and (B) 24 March 2004. Downwelling velocities were estimated from the pump rate versus downwelling velocity regression (Fig. 3). The 1:1 line (dotted line in both A and B: $y=0.879-0.020 x$ ) equates flume downwelling velocity estimates with mean vertical velocities (i.e. mean downwelling velocity estimates of passive particles would fall on this line). Observed mean vertical velocities (o) were estimated from video recorded larval swimming experiments and reflect net larval movements due to both downwelling and larval swimming. Corrected mean vertical velocities (•) reflect actual larval swimming velocities estimated as the difference between observed mean velocities and corresponding downwelling velocity (i.e. distance from the 1:1 line). The dashed line (---) relates downwelling velocity $\left(\mathrm{mm} \mathrm{s}^{-1}\right)$ to corrected mean vertical velocity $(\mathrm{A}: y=0.037+$ $\left.0.423 x, \mathrm{r}^{2}=0.975 ; \mathrm{B}: y=-1.819+0.480 x, \mathrm{r}^{2}=0.985\right)$

tested. Regression analysis revealed significant positive relationships between mean horizontal velocities $(y)$ and corresponding mean flume downwelling velocities $(x)$ for each experiment ( 4 March: $y=0.031 x-0.027, \mathrm{r}^{2}=0.614$, $\mathrm{p}=0.037 ; 28$ March: $y=0.056 x-0.363, \mathrm{r}^{2}=0.824, \mathrm{p}=$ 0.002). Because no horizontal flow velocities were measured, it is unclear whether larval horizontal velocities increased at higher downwelling rates owing to changes in behavior or to increased flow velocity variance.

\section{Larval behavior}

Cyprid trajectories in still water showed qualitatively that larvae had multiple distinct behavior modes 


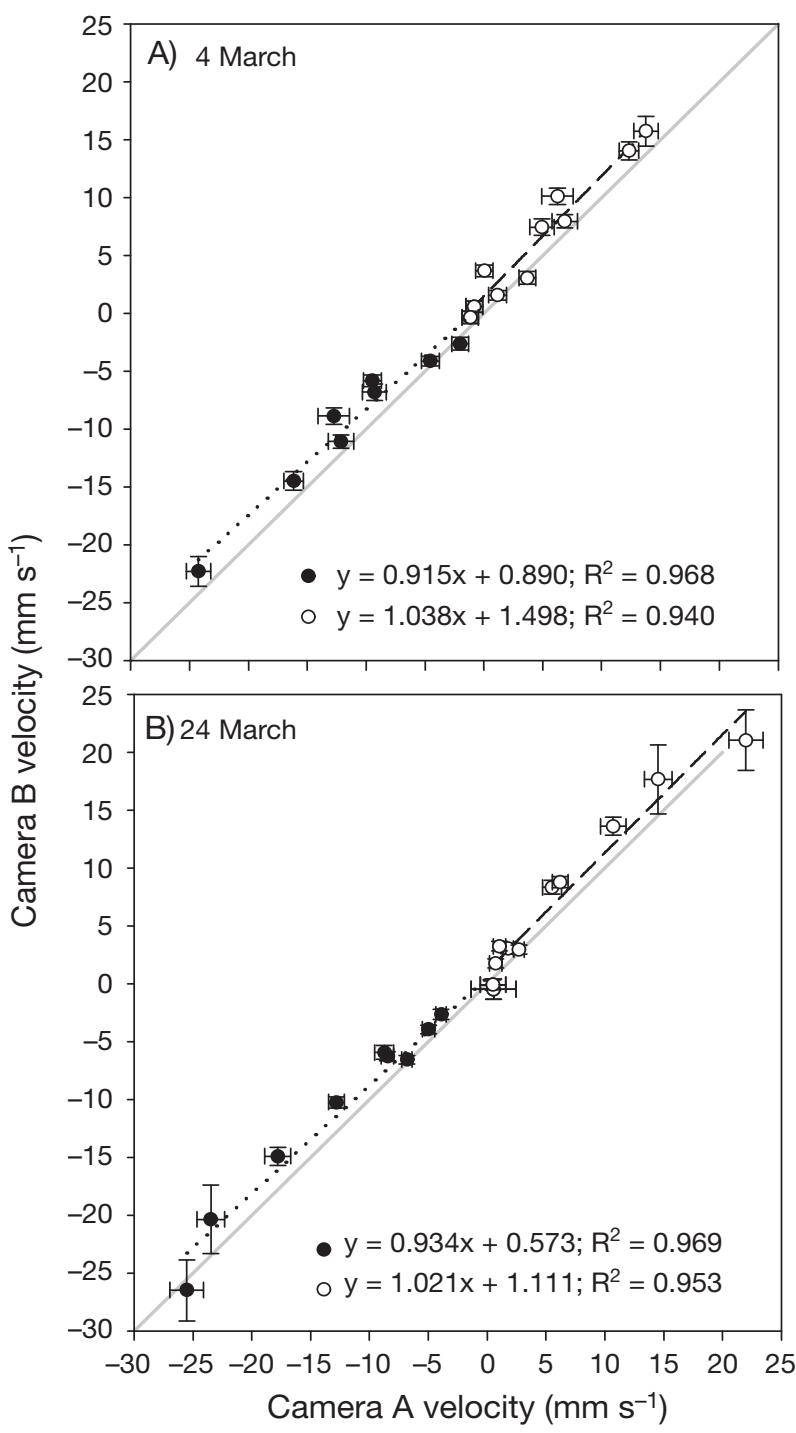

Fig. 7. Semibalanus balanoides. Observed (o) and corrected $(\bullet)$ mean cyprid vertical velocities $( \pm 1 \mathrm{SE})$ measured with orthogonally oriented digital video cameras (Cameras A and B) with overlapping field of views on (A) 4 March 2004 and (B) 24 March 2004. Each data point corresponds to mean velocities estimated at specific flume downwelling velocities. All points would fall on the 1:1 line (solid, grey) if both cameras observed the same larvae over the same time period; video recordings for Cameras A and B averaged 45 and 90 s, respectively. Dashed and dotted lines represent linear correlations with corresponding equations provided in the legends

(Fig. 8). Some larvae moved rapidly through the video frame in loose spirals or tortuous loops. Other larvae moved slowly, apparently trying to hold their positions, or alternated between slow swimming and passive sinking. Our statistical model enabled us to estimate the number of different behavior modes and the velocity distributions for each mode. As the downwelling velocity increased, cyprids continued to exhibit about the same number of behavior modes, but the flow-

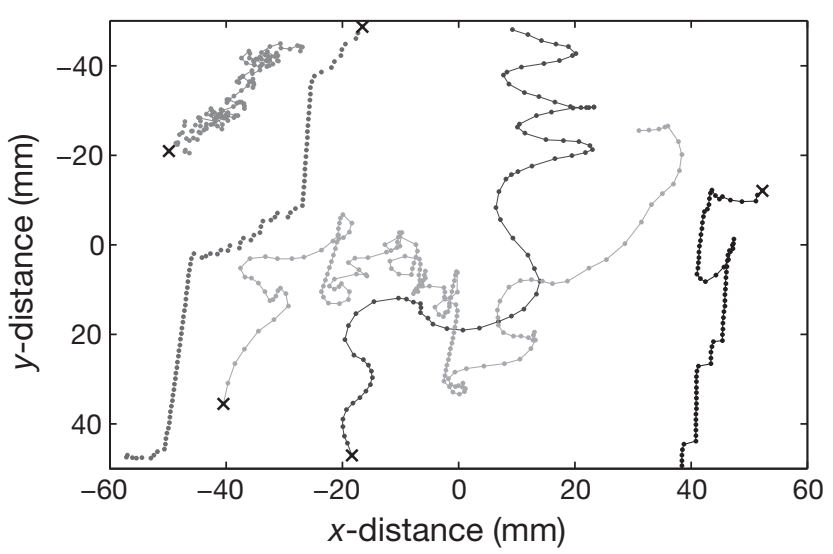

Fig. 8. Semibalanus balanoides. Representative cyprid trajectories in still water. An $\times$ marks the beginning of each track.

Data are from 4 March 2004, Replicate 1, Camera A

corrected mean velocities for these modes generally increased (Fig. 9), and the fastest group of larvae often swam up at speeds that nearly matched the downwelling flow. Overall mean cyprid velocities calculated from the mixture model and from the larval observations were nearly identical $\left(y=0.998 x+0.149, \mathrm{r}^{2}=\right.$ 0.995 , where $y$ is modeled mean velocity and $x$ is observed mean velocity in $\mathrm{mm} \mathrm{s}^{-1}$ ).

The total number of modes varied between treatments, ranging from $g=1$ to 4 , but most often there were 2 modes if both cameras are considered seperately (Fig. 10). When the number of modes differed between the 2 cameras, Camera B typically showed more modes than Camera A, probably because Camera B provided longer video records with more observations. Note that mode numbers do not correspond to specific behaviors, but for graphing purposes (Fig. 10) the modes are numbered in order of increasing mean velocity within each treatment. A mode with mean downward velocities of -6.7 to $-3.3 \mathrm{~mm} \mathrm{~s}^{-1}$ and SDs of 0.3 to $1.6 \mathrm{~mm} \mathrm{~s}^{-1}$ clearly corresponded to passive sinking and probably indicates a resting phase. This mode rarely appeared except in still water (Figs. 9 \& 10). In weaker downwelling flows there was another mode with a negative mean velocity $\left(-3.2\right.$ to $\left.-0.9 \mathrm{~mm} \mathrm{~s}^{-1}\right)$ but with larger SDs (1.8 to $10.9 \mathrm{~mm} \mathrm{~s}^{-1}$ ), probably representing larvae that swam in downward loops with occasional upward ambits. The resting and downward-swimming modes disappeared in stronger downwelling $\left(<-19 \mathrm{~mm} \mathrm{~s}^{-1}\right)$, but it is unclear whether larvae stopped doing these behaviors in strong flows or simply got washed out of the viewing area. The most common and persistent mode had mean velocities of $\sim 3$ to $\sim 12 \mathrm{~mm} \mathrm{~s}^{-1}$ and SDs of $\sim 4$ to $\sim 20 \mathrm{~mm} \mathrm{~s}^{-1}$, probably representing larvae that swam upward in loopy trajectories. This mode was observed at most treatment levels and may be a default behavior. At higher downwelling flows, generally $>1500 \mathrm{~Hz}$, an 
Table 3. Semibalanus balanoides. Corrected mean $( \pm \mathrm{SE})$ vertical larval velocities $\left(\mathrm{mm} \mathrm{s}^{-1}\right)$ and number of observations (in parentheses) per downwelling velocity treatment. Negative velocities indicate downwelled flume circulation and positive velocities indicate upward swimming by larvae. Larval tracks were recorded by orthogonally oriented video cameras with overlapping fields of view (Fig. 2). nd: no data collected

\begin{tabular}{|c|c|c|c|c|c|}
\hline \multirow{3}{*}{$\begin{array}{l}\text { Downwelling } \\
\text { velocity } \\
\left(\mathrm{mm} \mathrm{s}^{-1}\right)\end{array}$} & \multirow{3}{*}{$\begin{array}{c}\text { Replicate } \\
\text { number }\end{array}$} & \multicolumn{4}{|c|}{ Larval velocities $\pm \mathrm{SE}(\mathrm{N})$} \\
\hline & & \multicolumn{2}{|c|}{ Cyprids (4 March 2004) } & \multicolumn{2}{|c|}{ Cyprids (24 March 2004) } \\
\hline & & Camera A & Camera B & Camera A & Camera B \\
\hline 0 & 1 & $-0.817 \pm 0.711(76)$ & $0.582 \pm 0.485(175)$ & $0.540 \pm 1.905(23)$ & $-0.466 \pm 0.854(112)$ \\
\hline 0 & 2 & $-1.153 \pm 0.688(86)$ & $-0.348 \pm 0.507(186)$ & $0.502 \pm 1.087(48)$ & $-0.080 \pm 0.423(230)$ \\
\hline-5.11 & 1 & $3.681 \pm 0.707(107)$ & $3.065 \pm 0.551(190)$ & $0.721 \pm 0.535$ & $1.747 \pm 0.386(201)$ \\
\hline-5.11 & 2 & $1.151 \pm 0.766(118)$ & $1.565 \pm 0.398(366)$ & $1.782 \pm 0.439(126)$ & $3.040 \pm 0.437(175)$ \\
\hline-8.10 & 1 & $0.033 \pm 0.749(87)$ & $3.673 \pm 0.504(297)$ & $1.036 \pm 0.534(102)$ & $3.230 \pm 0.407(213)$ \\
\hline-8.10 & 2 & nd & nd & $2.687 \pm 0.439(330)$ & $2.936 \pm 0.385(468)$ \\
\hline-14.36 & 1 & $4.938 \pm 1.019(86)$ & $7.443 \pm 0.726(217)$ & $5.502 \pm 0.793$ & $8.322 \pm 0.593(200)$ \\
\hline-18.81 & 1 & $6.247 \pm 1.328(74)$ & $10.121 \pm 0.716(270)$ & $6.191 \pm 0.654(172)$ & $8.769 \pm 0.484(301)$ \\
\hline-18.81 & 2 & $6.865 \pm 1.070(128)$ & $7.942 \pm 0.581(355)$ & nd & nd \\
\hline-29.12 & 1 & $12.331 \pm 0.814(162)$ & $14.035 \pm 0.789(464)$ & $10.701 \pm 1.096(131)$ & $13.592 \pm 0.786(142)$ \\
\hline-41.48 & 1 & $13.758 \pm 1.033(192)$ & $15.722 \pm 1.294(268)$ & $14.521 \pm 1.161(53)$ & $17.657 \pm 2.974$ \\
\hline-47.29 & 1 & nd & nd & $21.975 \pm 1.437(195)$ & $21.035 \pm 2.630(27)$ \\
\hline
\end{tabular}

additional mode appeared with larger mean velocities of $\sim 15$ to $38 \mathrm{~mm} \mathrm{~s}^{-1}$ and a wide range of SDs (1.3 to $29.5 \mathrm{~mm} \mathrm{~s}^{-1}$ ). The fast modes with small SDs may represent larvae sprinting against the flow. Modes with SDs larger than the mean probably are not distinct behaviors but rather a spurious fit to sparse data in the long tails of the velocity distributions. At the highest downwelling rates one sprinting mode had mean velocities of 71.7 to $72.3 \mathrm{~mm} \mathrm{~s}^{-1}$, but this mode included only 4 to $7 \%$ of the population.

The normal mixture model generally provided a good fit to the velocity distributions, but results should be interpreted with caution. The observations ( $N=23$ to 486) were distributed over a wide range of velocities, so some distributions were gappy, particularly in the tails. Ideally we would have had many more (e.g. 1000s) observations. In general though, the velocity data within individual behavior modes were approximately normal, based on probability plots of velocities assigned with highest probability to individual modes. The exceptions were the modes containing $<5$ to $10 \%$ of the observations (e.g. the fastest sprinters) or those with large SDs (e.g. $>15 \mathrm{~mm} \mathrm{~s}^{-1}$ ), which had particularly gappy distributions. Although these exceptions may be spurious modes, we include them here because they could not be rejected by the likelihood ratio test.

\section{DISCUSSION}

\section{Swimming velocities and behavior}

The present study demonstrated that cyprids exhibit strong directional orientation to downwelling currents (rheotaxis) and that their mean upward (positive) swimming velocities increase at higher downwelling rates (Fig. 6). Cyprids attempted a depth-keeping behavior by swimming upward against downwelling currents. This upward swimming represents a different form of depth keeping than was observed in still water where cyprids alternated between swimming and sinking. The increase in mean upward swimming is considered a direct response to increasing downwelling (negative) velocities rather than phototaxis, because little or no phototaxis was observed in still water experiments (see below) and background lighting was constant. Our interpretation is that when faced with a strong downwelling flow, cyprids attempt to swim upward and occasionally 'sprint' against the flow to maintain their vertical position.

The ability of cyprids to sprint or otherwise alternate behaviors may offset the apparent inability to match downwelling velocities as indicated by cyprids' mean vertical velocities. Some cyprids were able to maintain their vertical position in the flume despite downwelling velocities and probably would be capable of exploiting shoreward propagating convergent zones. Whether cyprids succeed at depth keeping may also be related to energetic state (lipid reserves) and age. It is unclear how long an individual larva can maintain a sprint, but reported cyprid swimming velocities are sufficient (Crisp 1955, Yule 1982, present study) to match flume downwelling rates within the range tested.

Horizontal rheotaxis has been reported in many marine fishes (Arnold 1974), which typically turn and swim into oncoming currents. This behavior has been exploited in laboratory flume studies to characterize horizontal swimming rates (Leis 2006). Rheotaxis also has been reported in several marine invertebrate post- 

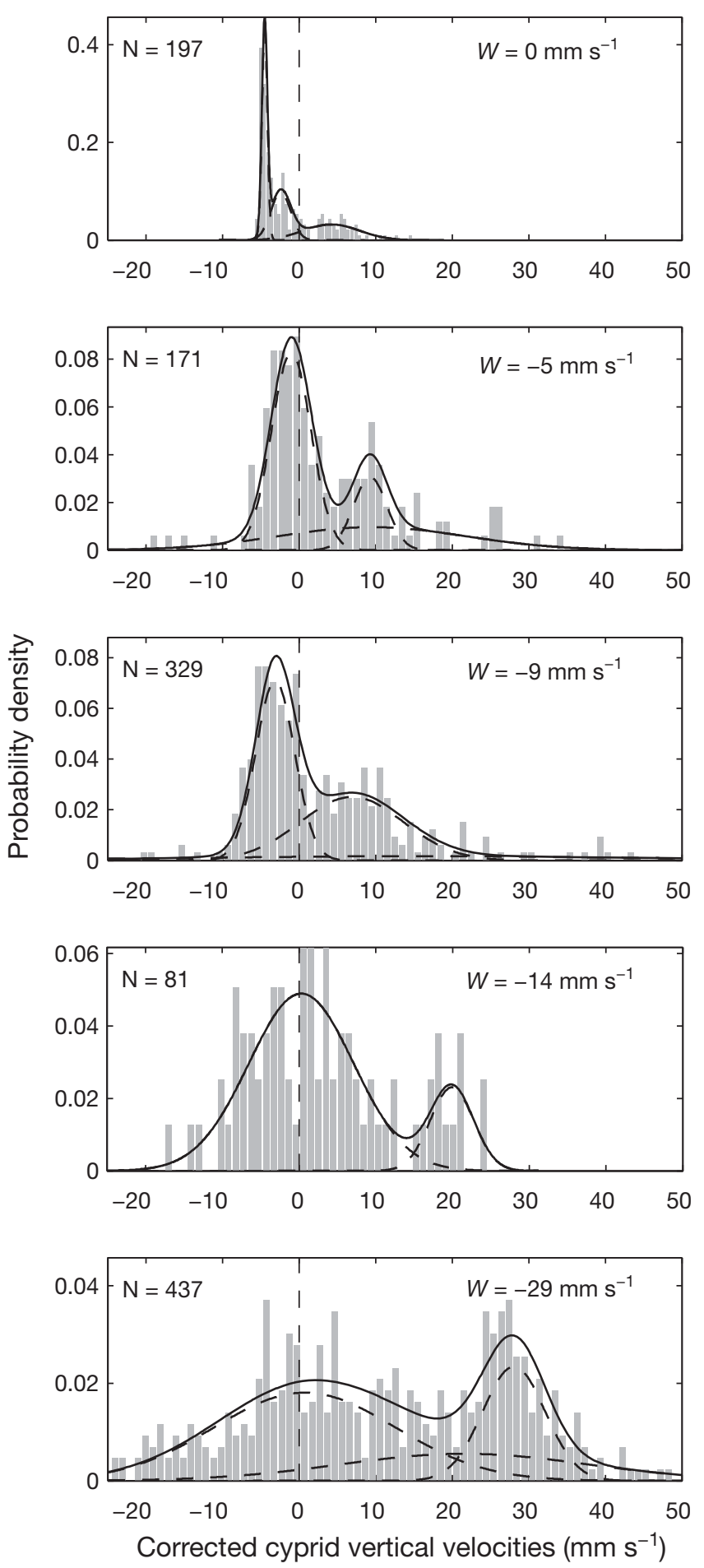

Fig. 9. Semibalanus balanoides. Representative cyprid data and mixture model fits for cyprids in still water and 4 downwelling rates (pump speeds: $300 \mathrm{~Hz}, 500 \mathrm{~Hz}, 750 \mathrm{~Hz}$, $1500 \mathrm{~Hz}$ ). Histograms show observed vertical velocity corrected for advection. Lines indicate probability density functions for individual modes distinguished by mixture model analysis (separate modes, dashed lines; combined modes, solid line). Number of observations and downwelling velocity $(W)$ from pump calibration are indicated larvae in response to in situ or laboratory-generated horizontal currents. Blue crab Callinectes sapidus megalopae are capable of sustained upstream swimming in currents up to $4.8 \mathrm{~cm} \mathrm{~s}^{-1}$ and able to hold their horizontal position rather than being swept downstream (Luckenbach \& Orth 1992). All lobster larval stages exhibit rheotaxis, but the response is weak in early stages (I-III) and strongest in postlarvae (Ennis 1986). Postlarval lobsters consistently orient into current flow in laboratory flumes but have no obvious directionality of swimming in still water (Cobb et al. 1989). Semibalanus balanoides cyprids in the present study likewise exhibited a lack of directional swimming in still water and an apparent rheotaxis in flow, but here the flow was vertical rather than horizontal.

Although horizontal rheotaxis is common in crustacean larvae, currents are often multidirectional or unpredictable, so other environmental cues are required to orient movement onshore (Ennis 1986, Cobb et al. 1989). For example, American lobster Homarus americanus larvae that swim shoreward towards settlement sites must be able to perceive the shore from several kilometers offshore (Cobb et al. 1989). Potential directional cues include differences in the quality of light over land versus the ocean (Cobb et al. 1989), polarized light (Ennis 1986), chemical cues (Hudon et al. 1986) and sound from waves breaking on the shore (Phillips \& Macmillan 1987, Macmillan et al. 1992). Though there are examples of onshore orientation and shoreward migrations by postlarval crustaceans, most marine invertebrate larvae seem to rely on shoreward advection by currents (Jeffs et al. 2005).

Shoreward advection would be facilitated by the vertical rheotaxis exhibited by Semibalanus balanoides cyprids in this study, even in the absence of directional cues. In still water, cyprids alternated between swimming and passive sinking, which would maintain their distribution in surface layers until they encountered a downwelling front. In downwelling flows, cyprids exhibited strong upward swimming that would enable them to maintain near-surface depths in passing fronts. Many coastal areas are dominated by shoreward-propagating convergence zones such as tidally generated internal waves and bores (Pineda 1994, Shanks 1995a). Because these hydrographic features occur regularly, larval behaviors may have adapted to use these physical mechanisms of shoreward transport. A simple rheotactic response to downwelling currents would facilitate entrainment in fronts; larvae that sprint part of the time should be better adapted for depth keeping in fronts than larvae that ignore the flow.

Depth regulation by marine invertebrate larvae generally relies on swimming or sinking in response to cues that indicate vertical direction (Sulkin 1984, 
04 March Replicate 1
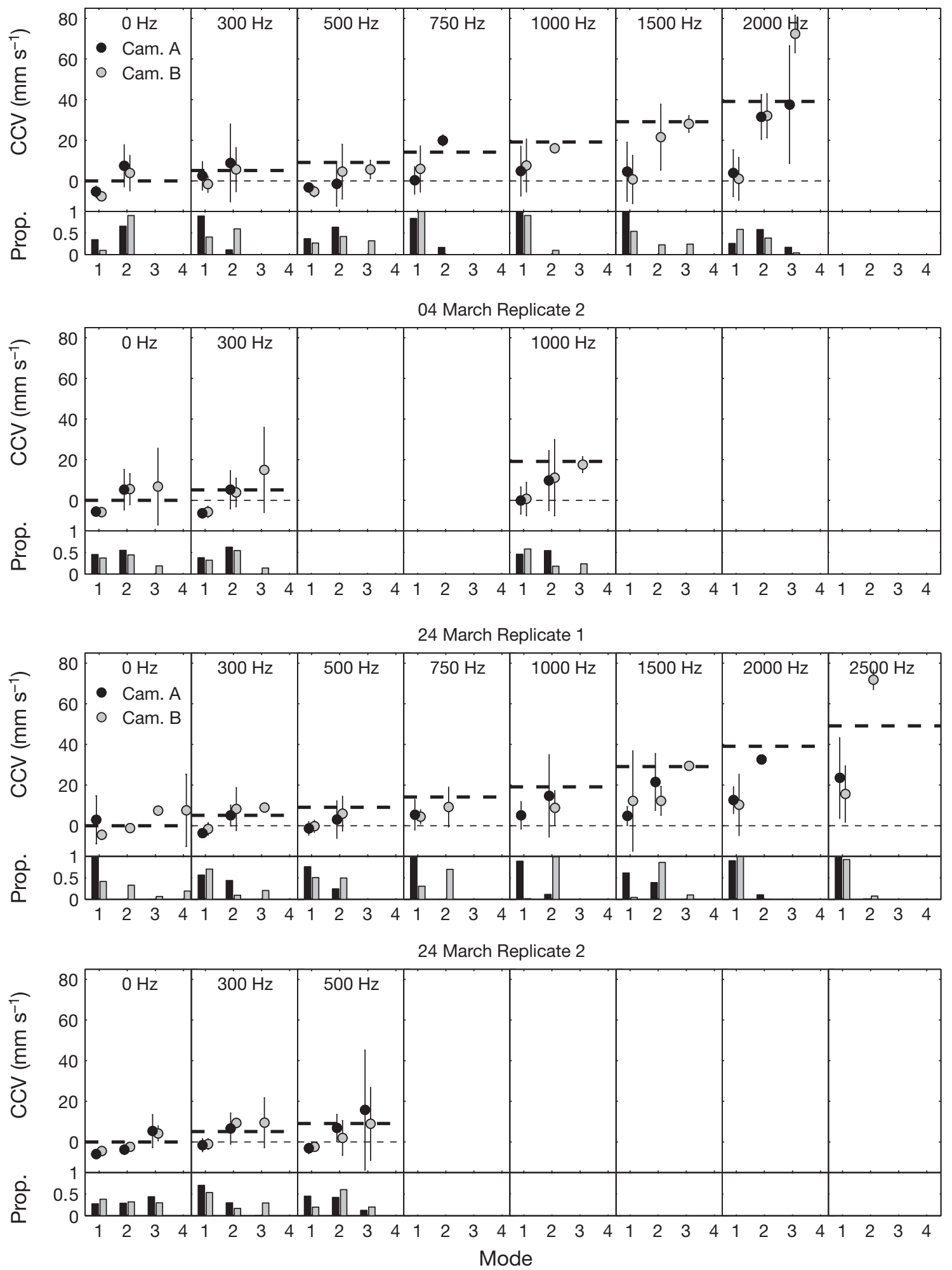

Fig. 10. Semibalanus balanoides. Mean velocities $( \pm 1 \mathrm{SD})$ for behavior modes distinguished by mixture model analysis at all treatments. Data shown for both cameras (Camera A, black symbols; Camera B, grey symbols). Thin dashed lines indicate zero velocity; thick dashed lines indicate downwelling (negative) velocity. Bar graphs below each plot show the proportion of larvae estimated to be in each mode. Replicated treatments for each day are shown in separate panels. Prop. $=$ proportion; $\mathrm{CCV}=\mathrm{corrected}$ 
reviewed by Forward 1988). Cyprids, zoeae, and most other invertebrate larvae are negatively buoyant with few exceptions (Chia et al. 1984) and there is little evidence that they can maintain depth by regulating buoyancy. They are generally thought to rely on locomotor responses, including swimming and sinking, mediated by environmental cues (e.g. Sulkin 1984). Brachyuran crab larvae, for example, orient to gravity (geotaxis) and swim upwards or sink in response to pressure increases and decreases (barokinesis), respectively (Sulkin 1973, 1984). Semibalanus balanoides cyprids exhibit high barokinesis with a low response threshold, which may enable them to regulate depth by swimming upwards when pressure rises and sinking when pressure falls (Rice 1964, KnightJones \& Morgan 1966, Knight-Jones \& Qasim 1966). Although upward swimming is typically oriented towards light rather than gravity (Rice 1964), cyprids have been shown to orient to gravity in the absence of light (Knight-Jones \& Morgan 1966, Knight-Jones \& Qasim 1966). Light and gravity were held constant in the present study, making it difficult to identify a primary directional cue used for depth keeping.

Many plankton respond to small changes in pressure (e.g. 5 to 15 mb, Knight-Jones \& Morgan 1966), and these sensitive responses would enable depth keeping within the downwelling flume's $75 \mathrm{~cm}$ depth range. For example, Knight-Jones \& Qasim (1966) showed that cyprids maintained their depth within fairly narrow limits by frequently alternating between swimming and sinking. Cyprids stopped swimming upwards and sank in response to drops in pressure as small as $10 \mathrm{mb}$, equivalent to an upwards migration of about $10 \mathrm{~cm}$. The same cyprids continued to sink until they experienced an increase in pressure that was comparable in magnitude with the previous drop (again ca. $10 \mathrm{~cm}$ ), which then elicited upward swimming. This low response threshold to pressure suggests that depth-keeping mechanisms may be regulated over shallow depth ranges. The cyprids used in this study were collected in surface waters $(<75 \mathrm{~cm})$ and may have been predisposed to maintain their depth within the observational region of the chamber using pressure changes.

Phototaxis is another commonly observed orientation behavior in zooplankton, but for many species the response is a laboratory artifact resulting from stimulation with abnormally bright and focused beams of light (Forward 1988). Semibalanus balanoides cyprids hardly swim in the lab in the absence of a strong light stimulus (Crisp 1955), and lights used in the present study were relatively weak. Fluorescent tube lights provided diffuse backlighting to enhance contrast in digital images, but there was no evidence that these lights elicited phototaxis from cyprids. Instead of swimming towards the light source, cyprids swam in random paths in the horizontal plane (data not shown) at very low mean swim velocities $\left(<1 \mathrm{~mm} \mathrm{~s}^{-1}\right)$. Overhead lighting was a greater concern because of reports that cyprids aggregate in surface waters owing to photopositive behavior (Stubbings 1975), but overhead lights were turned off near the flume. In still water, individual cyprids remained within the camera's field of view for extended periods as they swam in loopy paths or alternated between swimming and sinking. The mean vertical swimming velocities were near zero, indicating that there was no net movement due to phototaxis. Of the directional cues present in our experiments (i.e. phototaxis, rheotaxis and barokinesis) light was probably the least likely to have elicited observed swimming responses.

\section{Experimental considerations}

The downwelling flume is a novel apparatus that enabled us to observe behaviors of many larvae (100s to 1000s) simultaneously in a vertical flow. These observations of larvae over extended periods (45 to $90 \mathrm{~s}$ ) yield more realistic velocity estimates than the 'stopwatch' methods typically used to measure swimming or sinking rates of larvae in small containers (reviewed by Chia et al. 1984). Previous studies of Semibalanus balanoides cyprids used focused light beams to elicit phototaxis over short distances and time periods (seconds) (Crisp 1955, Walker 2004). Those studies produced mean velocity estimates 2.5 times higher than the ones we observed, and our results more accurately represent sustained swimming speeds.

The flume is larger than the observational region defined by the camera's field of view, so our velocity estimates include only the larvae that remained within the video-recorded region of the chamber. Larvae that swam upward or that sank owing to gravity were unobserved after they were lost from the observational region. Individuals may have contributed multiple times to estimated mean swimming rates if they left and re-entered the field of view. Because the flow was unidirectional, randomly swimming larvae would be more likely to leave the observational region by being washed out than by swimming upward. Cyprids actually had a net accumulation in the field of view, suggesting that our results were biased toward more positive values (see Fig. 6) and a greater proportion of larvae in upward swimming modes. In fact, more cyprids entered the field of view through the top than left through the bottom. The number of larvae that entered or left the field of view through the sides was 
negligible. Near neutrally buoyant (passive) Pliolite ${ }^{\circledR}$ particles had no net accumulation. The accumulation of larvae within the observation region indicates that cyprids were actively moving upward to maintain depth rather than being washed away.

The number of healthy, viable larvae available for laboratory experiments is often limited by their availability from natural sources. Larvae typically make up a small proportion of the total number of individuals collected in a plankton sample, which must be identified to species level microscopically. This is a timeconsuming process, and many researchers either resign themselves to small sample sizes or to culturing larvae in the laboratory. For example, Walker \& Lester (2000) estimated cyprid swimming rates from 20 individuals raised in a single batch culture. These few laboratory-reared larvae may not represent the inherent variability in cyprid swimming rates or behavior, and laboratory-reared larvae swim significantly slower than field-sampled ones (Cobb et al. 1989). In the present study, larval swimming rates were typically estimated from concurrent observations of >100 larval swim tracks per treatment replicate, and cyprids were used within $30 \mathrm{~h}$ of being collected in the field. Although field-collected larvae might be expected to have variable behaviors, we observed statistically similar mean swimming velocities and behavior modes in cyprids sampled 3 wk apart, suggesting that our results are robust.

\section{Significance of cyprid behavior}

The accumulation of zooplankton in frontal zones has been explained as depth-keeping behavior by organisms capable of swimming against downwelling currents (Franks 1992, Epstein \& Beardsley 2001). In the case of meroplankton, cyprids and other larvae are significantly more abundant in convergence zones when compared with shoreward and offshore sides of the convergent features (Shanks \& Wright 1987, Pineda 1999). Genin et al. (2005) provided direct evidence that zooplankton were capable of swimming against downwelling currents by acoustically tracking organisms in situ while simultaneously measuring ambient currents. Semibalanus balanoides cyprids in the present study swam upwards when exposed to downwelling flows, a response that is consistent with the inferred behavior of Pollicipes polymerus and Chthamalus spp. cyprids sampled in internal tidal bore warm fronts (Pineda 1999). Shore crab Pachygrapsus crassipes megalopae can maintain their position in the neuston via positive phototaxis, negative geotaxis and high barokinesis and photokinesis (Shanks 1985). Shanks (1985) hypothesized that the strong swimming ability of $P$. crassipes megalopae $\left(\sim 10 \mathrm{~cm} \mathrm{~s}^{-1}\right)$ could allow them to maintain their position in the neuston and, as a result, aggregate in passing convergent fronts, ultimately resulting in shoreward transport.

The effect of vertical buoyancy or swimming capabilities on the accumulation and transport of plankton by propagating fronts has been investigated in laboratory and numerical modeling studies (Helfrich \& Pineda 2003, Scotti \& Pineda 2007). Particles (and planktonic larvae) retained in surface layers with sufficient buoyancy (or vertical swimming abilities) experienced accumulation and shoreward transport in convergent zones associated with frontal features (Helfrich \& Pineda 2003). Scotti \& Pineda (2007) incorporated swimming behaviors based on preliminary observations from the present study in a 3-dimensional hydrodynamic model of gravity currents and nonlinear waves. Model results showed that observed upward swimming velocities were sufficient for larvae to accumulate and be transported onshore by nonlinear internal fronts. They also showed that the accumulation and shoreward transport was possible for larvae with sustained upward swimming speeds in the range of 0.1 to $10 \mathrm{~mm} \mathrm{~s}^{-1}$, well within swimming velocities documented for Semibalanus balanoides cyprids in our study.

Although empirical data are limited, it is reasonable to assume that downwelling velocities in convergence zones may be only a few centimeters per second. Vertical currents were up to $\sim 4 \mathrm{~cm} \mathrm{~s}^{-1}$ during extended periods of downwelling in the Red Sea (Genin et al. 2005) while downwelling currents estimated from the velocity of vertical deformation of the thermocline averaged 4.75 to $4.90 \mathrm{~cm} \mathrm{~s}^{-1}$ (Zeldis \& Jillett 1982, Shanks 1985). These estimates are only slightly greater than the maximum downwelling speed used in our study. Semibalanus balanoides cyprids were able to swim against these flows suggesting they swim well enough to maintain themselves within surface frontal zones and benefit from onshore transport.

Downwelling convergent circulation may accumulate flotsam that is sufficiently buoyant to resist downwelling in frontal convergent features (Ewing 1950, Arthur 1954, Shanks 1983). Examples of flotsam include natural (algae) as well as anthropogenic materials (Styrofoam) along with attached organisms (Kingsford \& Choat 1986, Shanks 1995a). Thigmotactic larvae, including crab megalopae (Shanks 1985 and references cited therein), may cling to flotsam and maintain themselves in surface layers without swimming. These organisms as well as the flotsam would be transported in surface layers by winds, currents and downwelling convergent fronts as long as the onshore horizontal surface current velocity $(u)$ is faster than the propagation speed $(C)$ of the convergent feature. 
In southern California, Pineda $(1994,1999)$ estimated that internal tidal bore warm fronts propagate no more than 1.5 to $2.5 \mathrm{~km}$ from offshore waters to the surf zone. At an average propagating speed of $14.8 \mathrm{~cm} \mathrm{~s}^{-1}$ (Pineda, 1999), assuming constant velocity, this would take about 169 to $282 \mathrm{~min}$. This range represents a conservative estimate for the time required for larvae to get to shore since cyprid larvae are often within 300 to $600 \mathrm{~m}$ of the shore (Tapia \& Pineda 2007).

The relative position (meters) of larvae in different regions of shoreward propagating fronts has not been documented in situ for logistical reasons. These issues have been studied and described by Helfrich \& Pineda (2003) and Scotti \& Pineda (2007). Rather than holding 'permanently' to fronts, most larvae probably recirculate in the broad frontal area. It is likely that larvae are (1) initially pushed to the leading edge as surface current velocity in the direction of front propagation $(u)$ is larger than the propagation speed of the front $(c)$, then (2) swept down and away from the leading edge by the frontal downwelling turbulent circulation, and finally (3) swim up and reach the front again, as $u>c$. Whether there are vertical currents that are too strong for cyprid larvae is unknown, but this question may someday be resolved through a better understanding of dynamics at the leading edge of a front.

The 'swim and sink' behavior observed for Semibalanus balanoides cyprids is similar to the 'hop and sink' strategy initially described for calanoid copepods (Bainbridge 1952). It is more energy efficient to alternate between swimming upwards and sinking downwards than to keep depth by continuous swimming if organisms can slow their rate of descent by increasing drag during sinking (Haury \& Weihs 1976). Copepods increase drag by spreading their antennae during sinking and fold them away to reduce drag while swimming upwards (Alexander 1990). S. balanoides cyprids sink $\sim 18.5 \%$ slower with open carapaces and extended limbs than with closed carapaces during a passive descent (Yule 1982). Cyprids swim with their thoracic limbs by rapidly accelerating forward on the backward stroke and equally rapidly decelerating during the recovery stroke. Yule (1982) estimated that about $29 \%$ of the energy exerted on the power stroke was used to counter negative thrust on the recovery stroke. This inefficiency enhances apparent benefits from a 'swim and sink' strategy, especially since cyprids do not feed and rely entirely on lipid energy reserves gained during naupliar development (Holland \& Walker 1975).

Another potential benefit of 'swim and sink' behavior is increased stability. Negatively buoyant organisms with no means of orientation when swimming can continually return to a consistent or stable position through a series of upwardly inclined jumps (Lochhead 1942), suggesting that the sinking phase may enable an organism to orient to gravity. Knight-Jones \& Qasim (1966) observed that Semibalanus balanoides cyprids sank dorsal side downwards and that a short swimming burst reoriented cyprids anterior end upwards within the first few strokes. This provides a simple mechanism for cyprids to orient upwards with respect to gravity and or light and facilitate depth-keeping or vertical migratory behavior.

When exposed to downwelling flow, cyprids exhibited individual variation in behaviors and swimming velocities, suggesting that larvae in situ have variable abilities to exploit shoreward-propagating fronts. Although cyprid swimming velocities were comparable with downwelling velocities in situ (Shanks 1985, Genin et al. 2005), we expect that only a fraction of cyprids will be transported by fronts. The rate and duration of sustained upward swimming velocities by cyprids, together with the turbulent circulation in the leading edge of the fronts, will determine how long larvae will be able to remain within frontal zones and ultimately how far they will be transported. Internal waves decompose from a solitary wave into a set of waves that propagate shoreward in packets (Haury et al. 1979, Pineda 1991). Larvae that maximize time spent within each convergent zone and that take advantage of successive convergent features should experience the greatest transport. The relative viability of larvae spawned at different times of the year or exposed to different ambient conditions in the plankton (e.g. temperature, food concentration) can significantly influence the proportion of in situ larvae that will be able to be transported onshore and ultimately recruit successfully.

Acknowledgements. We are grateful to J. Sisson for constructing the flume and for making LDV measurements. H. Richmond, V. Starczak and F. Tapia assisted with in situ zooplankton collections and timely sorting of barnacle larvae for laboratory experiments. V. Starczak provided statistical advice while T. Bird and K. Bradley assisted with laboratory experiments. Funding for this research was provided through a US National Science Foundation Biocomplexity Grant (OCE-0083976) to J.P.

\section{LITERATURE CITED}

Alexander RM (1990) Size, speed and buoyancy adaptations in aquatic animals. Am Zool 30:189-196

Amsler MO, Amsler CD, Rittschof D, Becerro MA, Mcclintock JB (2006) The use of computer-assisted motion analysis for quantitative studies of the behaviour of barnacle (Balanus amphitrite) larvae. Mar Freshwat Behav Physiol 39: 259-268

> Arnold GP (1974) Rheotropism in fishes. Biol Rev Camb Philos Soc 49:515-576

Arthur RS (1954) Oscillation in sea temperature at Scripps and Oceanside Piers. Deep-Sea Res 2:129-143 
Bainbridge R (1952) Underwater observations on the swimming of marine zooplankton. J Mar Biol Assoc UK 31: $107-112$

Chia FS, Buckland-Nicks J, Young C (1984) Locomotion in marine invertebrate larvae: a review. Can J Zool 62: 1205-1222

Cobb JS, Wang D, Campbell DB, Rooney P (1989) Speed and direction of swimming by postlarvae of the American lobster. Trans Am Fish Soc 118:82-86

Crisp DJ (1955) The behaviour of barnacle cyprids in relation to water movement over a surface. J Exp Biol 32:569-590

- DiBacco C, Sutton D, McConnico L (2001) Vertical migration behavior and horizontal distribution of brachyuran larvae in a low inflow estuary: implications for bay-ocean exchange. Mar Ecol Prog Ser 217:191-206

Eggleston DB, Armstrong DA, Elis WE, Patton WS (1998) Estuarine fronts as conduits for larval transport: hydrodynamics and spatial distribution of Dungeness crab postlarvae. Mar Ecol Prog Ser 164:73-82

Ennis GP (1986) Swimming ability of larval American lobsters, Homarus americanus, in flowing water. Can J Fish Aquat Sci 43:2177-2183

Epifanio CE (1988) Transport of invertebrate larvae between estuaries and the continental shelf. Am Fish Soc Symp 3:104-114

Epifanio CE, Garvine RW (2001) Larval transport on the Atlantic continental shelf of North America: a review. Estuar Coast Shelf Sci 52:51-77

Epstein AW, Beardsley RC (2001) Flow-induced aggregation of plankton at a front: a 2-D Eulerian model study. DeepSea Res II 48:395-418

Ewing G (1950) Slicks, surface films and internal waves. J Mar Res 9:161-187

Farrell TM, Bracher D, Roughgarden J (1991) Cross-shelf transport causes recruitment to intertidal populations in central California. Limnol Oceanogr 36:279-288

Forward RBJ (1988) Diel vertical migration: zooplankton photobiology and behaviour. Oceanogr Mar Biol Annu Rev 26:361-393

Franks PJS (1992) Sink or swim: accumulation of biomass at fronts. Mar Ecol Prog Ser 82:1-12

Franks P (1997) Spatial patterns in dense algal blooms. Limnol Oceanogr 42:1297-1305

Fuchs HL, Mullineaux LS, Solow AR (2004) Sinking behavior of gastropod larvae (Ilyanassa obsoleta) in turbulence. Limnol Oceanogr 49:1937-1948

Fuchs HL, Solow AR, Mullineaux LS (2010) Larval responses to turbulence and temperature in a tidal inlet: habitat selection by dispersing gastropods? J Mar Res 68: 153-188

Genin A, Jaffe JS, Reef R, Richter C, Franks PJS (2005) Swimming against the flow: a mechanism of zooplankton aggregation. Science 308:860-862

Haury L, Weihs D (1976) Energetically efficient swimming behavior of negatively buoyant zooplankton. Limnol Oceanogr 21:797-803

Haury LR, Briscoe MG, Orr MH (1979) Tidally generated internal wave packets in Massachusetts Bay. Nature 278: 312-317

Helfrich KR, Pineda J (2003) Accumulation of particles in propagating fronts. Limnol Oceanogr 48:1509-1520

Holland DL, Walker G (1975) Biochemical composition of cypris larva of barnacle Balanus balanoides L. ICES J Mar Sci 36:162-165

Hudon C, Fradette P, Legendre P (1986) La repartition horizontale et verticale des larves de homard (Homarus americanus) autour des iles de la Madeleine, golfe du Saint-
Laurent. Can J Fish Aquat Sci 43:2164-2176

Jeffs AG, Montgomery JC, Tindle CT (2005) How do spiny lobster post-larvae find the coast? N Z J Mar Freshw Res 39:605-617

Kingsford MJ, Choat JH (1986) Influence of surface slicks on the distribution and onshore movements of small fish. Mar Biol 91:161-171

Knight-Jones EW, Morgan E (1966) Responses of marine animals to changes in hydrostatic pressure. Oceanogr Mar Biol Annu Rev 4:267-299

Knight-Jones EW, Qasim SZ (1966) Responses of Crustacea to changes in hydrostatic pressure. Proc Symp Crustac Mar Biol Assoc India 3:1132-1150

Leis JM (2006) Are larvae of demersal fishes plankton or nekton? Adv Mar Biol 51:59 -141

Lochhead JR (1942) Control of swimming position by mechanical factors and proprioception. Q Rev Biol 17:12-30

> Luckenbach MW, Orth RJ (1992) Swimming velocities and behavior of blue crab (Callinectes sapidus Rathburn) megalopae in still and flowing water. Estuaries 15: 186-192

> Macmillan DL, Phillips BF, Coyne JA (1992) Further observations on the antennal receptors of rock lobsters and their possible involvement in puerulus stage navigation. Mar Behav Physiol 19:211-225

McLachlan GT (1987) On bootstrapping the likelihood ratio test statistic for the number of components in a normal mixture. J R Stat Soc Ser C Appl Stat 36:318-324

McLachlan GT, Peel D (2000) Finite mixture models. John Wiley \& Sons, New York, NY

> Phillips BF, Macmillan DL (1987) Antennal receptors in peurulus and postpuerulus stages of the rock lobster Panulirus cygnus (Decapoda, Palinuridae) and their potential role in puerulus navigation. J Crustac Biol 7: $122-135$

> Pineda J (1991) Predictable upwelling and shoreward transport of planktonic larvae by internal tidal bores. Science 253:548-551

> Pineda J (1994) Internal tidal bores in the nearshore: warmwater fronts, seaward gravity currents and the onshore transport of neustonic larvae. J Mar Res 52:427-458

Pineda J (1999) Circulation and larval distribution in internal tidal bore warm fronts. Limnol Oceanogr 44:1400-1414

Pineda J, Riebensahm D, Medeiros-Bergen D (2002) Semibalanus balanoides in winter and spring: larval concentration, settlement, and substrate occupancy. Mar Biol 140: $789-800$

Rice AL (1964) Observations on the effects of changes of hydrostatic pressure on the behavior of some marine animals. J Mar Biol Assoc UK 44:163-175

Scheltema RS (1986) On dispersal and planktonic larvae of benthic invertebrates: an eclectic overview and summary of problems. Bull Mar Sci 39:290-322

Scotti A, Pineda J (2007) Plankton accumulation and transport in propagating nonlinear internal fronts. J Mar Res 65: $117-145$

Shanks AL (1983) Surface slicks associated with tidally forced internal waves may transport pelagic larvae of benthic invertebrates and fishes shoreward. Mar Ecol Prog Ser 13:311-315

> Shanks AL (1985) Behavioral basis of internal-wave-induced shoreward transport of megalopae of the crab Pachygrapsus crassipes. Mar Ecol Prog Ser 24:289-295

> Shanks AL (1986) Tidal periodicity in the daily settlement of intertidal barnacle larvae and an hypothesized mechanism for the cross-shelf transport of cyprids. Biol Bull (Woods Hole) 170:429-440 
Shanks AL (1988) Further support for the hypothesis that internal waves can cause shoreward transport of larval invertebrates and fish. Fish Bull 86:703-714

Shanks AL (1995a) Mechanisms of cross-shelf dispersal of larval invertebrates and fish. In: McEdward LR (ed) Ecology of marine invertebrate larvae. CRC Press, Boca Raton, FL, p 323-367

Shanks AL (1995b) Oriented swimming by megalopae of several eastern north Pacific crab species and its potential role in their onshore migration. J Exp Mar Biol Ecol 186: $1-16$

Shanks AL, Wright WG (1987) Internal-wave-mediated shoreward transport of cyprids, megalopae, and gammarids and correlated longshore differences in the settling rate of intertidal barnacles. J Exp Mar Biol Ecol 114:1-13

Stubbings HG (1975) Balanus balanoides, Vol 37. Liverpool University Press, Liverpool

Sulkin SD (1973) Depth regulation of crab larvae in the absence of light. J Exp Mar Biol Ecol 13:73-82

Sulkin SD (1984) Behavioral basis of depth regulation in the larvae of brachyuran crabs. Mar Ecol Prog Ser 15:181-205

Editorial responsibility: Steven Morgan,

Bodega Bay, California, USA
Tapia F, Pineda J (2007) Stage-specific distribution of barnacle larvae in nearshore waters: potential for limited dispersal and high mortality rates. Mar Ecol Prog Ser 342:177-190

Vogel S (1994) Life in moving fluids. Princeton University Press, Princeton, NJ

Walker G (2004) Swimming speeds of the larval stages of the parasitic barnacle, Heterosaccus lunatus (Crustacea: Cirripedia: Rhizocephala). J Mar Biol Assoc UK 84: 737-742

Walker G, Lester RJG (2000) The cypris larvae of the parasitic barnacle Heterosaccus lunatus (Crustacea, Cirripedia, Rhizocephala): some laboratory observations. J Exp Mar Biol Ecol 254:249-257

> Wernet M, Pline A (1993) Particle displacement tracking technique and Cramer-Rao lower bound error in centroid estimates from CCD imagery. Exp Fluids 15:295-307

Yule AB (1982) The application of new techniques to the study of planktonic organisms. PhD thesis, University College of North Wales, Bangor

Zeldis JR, Jillett JB (1982) Aggregation of pelagic Munida gregaria (Fabricus) (Decapoda, Anomura) by coastal fronts and internal waves. J Plankton Res 4:839-857

Submitted: November 17, 2010; Accepted: April 28, 2011

Proofs received from author(s): July 7, 2011 